\title{
Escherichia coli 0157:H7 Induces Stronger Plant Immunity than Salmonella enterica Typhimurium SL1344
}

\author{
Debanjana Roy, Shweta Panchal, Bruce A. Rosa, and Maeli Melotto
}

First, second, and fourth authors: Department of Biology, University of Texas, Arlington 76019; and third author: The Genome Institute, Washington University School of Medicine, St. Louis, MO 63102. Accepted for publication 30 December 2012.

\begin{abstract}
Roy, D., Panchal, S., Rosa, B. A., and Melotto, M. 2013. Escherichia coli O157:H7 induces stronger plant immunity than Salmonella enterica Typhimurium SL1344. Phytopathology 103:326-332.

Consumption of fresh produce contaminated with bacterial human pathogens has resulted in various, sometimes deadly, disease outbreaks. In this study, we assessed plant defense responses induced by the fully pathogenic bacteria Escherichia coli $\mathrm{O} 157: \mathrm{H} 7$ and Salmonella enterica serovar Typhimurium SL1344 in both Arabidopsis thaliana and lettuce (Lactuca sativa). Unlike SL1344, O157:H7 induced strong plant immunity at both pre-invasion and post-invasion steps of infection. For instance, O157:H7 triggered stomatal closure even under high relative

humidity, an environmental condition that generally weakens plant defenses against bacteria in the field and laboratory conditions. SL1344 instead induced a transient stomatal immunity. We also observed that $P R I$ gene expression was significantly higher in Arabidopsis leaves infected with O157:H7 compared with SL1344. These results suggest that plants may recognize and respond to some human pathogens more effectively than others. Furthermore, stomatal immunity can diminish the penetration of human pathogens through the leaf epidermis, resulting in low bacterial titers in the plant apoplast and suggesting that additional control measures can be employed to prevent food contamination. The understanding of how plant responses can diminish bacterial contamination is paramount in preventing outbreaks and improving the safety of food supplies.
\end{abstract}

The number of serious cases of food contamination leading to death has been increasing, and outbreaks associated with fresh produce have emerged as an important public health concern. It is estimated that 76 million cases of foodborne diseases occur yearly in the United States (4). In particular, Escherichia coli and Salmonella enterica appear to be two of the most common causal agents of food poisoning associated with the consumption of fresh leafy vegetables (28). The enterohemorrhagic E. coli O157:H7 (hereafter referred to as 0157:H7) causes bloody diarrhea and hemolytic uremic syndrome and $S$. enterica serovar Typhimurium causes gastroenteritis. These human pathogens are not known to be plant pathogens (1). Nonetheless, they can survive on and penetrate into plant tissues and maintain their population in the mesophyll, causing serious foodborne disease outbreaks. Both surface and interior contamination of leaves with human pathogens can be dangerous but internal contamination is difficult, if not impossible, to remove by standard disinfection procedures. Therefore, the understanding of the initial contamination process is paramount in preventing foodborne diseases.

Several studies have shown association of Salmonella spp. and O157:H7 with stomata and naturally occurring lesions $(3,8,14$, 17). Wounds also provide a nutrient-rich path toward the plant interior (9). However, in the absence of wounding, a major unsolved issue is how human pathogens internalize plant tissue (7) and cope with the active innate immune system against nonpathogens. To fight infection, plants rely on the innate immunity consisting of two main branches (15), pathogen-triggered immunity (PTI) and effector-triggered immunity (ETI). In PTI, conserved molecular signatures of microorganisms called pathogen- or microbe-associated molecular patterns (PAMPs or MAMPs)

Corresponding author: M. Melotto; E-mail address: melotto@uta.edu

http://dx.doi.org/10.1094/PHYTO-09-12-0230-FI

(c) 2013 The American Phytopathological Society are recognized by plant receptors called pattern recognition receptors. Recognition leads to activation of defense signaling pathways in the plant cell, including plant hormone-dependent as well as hormone-independent signaling pathways (6). The hormones jasmonate, salicylic acid, and ethylene are particularly important (10). Successful virulent phytopathogens are able to overcome PTI by different virulence strategies such as the production of type III secretion system effectors and phytotoxins (20). In incompatible interactions, effectors released by the pathogen into the plant cell are recognized by specific nucleotide-binding leucinerich repeat proteins encoded by resistance genes, which results in ETI, a strong response leading to hypersensitive reaction that limits pathogen spread to other tissues.

PTI is considered to be the first line of defense against microbial attack. One of the important components in this initial defense against pathogens is stomatal immunity. The stomatal pore is a prevalent opening in the leaf epidermis (21) that is crucial in allowing gas exchange necessary for photosynthesis and is also a major route for bacterial penetration into plant tissue. Stomata function as active innate immunity gates against invasion of bacteria into Arabidopsis leaves (29). Previous studies suggest that $\mathrm{O} 157: \mathrm{H} 7$ cannot overcome stomatal closure, resulting in prolonged activation of the stomatal immune response (22). Interestingly, however, a recent study documented a remarkable ability of S. enterica serovar Typhimurium SL1344 (hereafter referred to as SL1344) to migrate toward stomata and enter plant tissues without triggering the stomatal immune response (17). This finding is both unexpected and exciting, raising the possibility that not only plant pathogens $(11,12,22,30)$ but also some human pathogens (SL1344) have evolved mechanisms to subvert stomatal defense to enter plant tissues. However, it is equally possible that this bacterium is able to evade recognition by the plant immune system. In either case, the response of plants toward infection by SL1344 seems to be different than that toward O157:H7. At this point, this observation remains an intriguing phenomenon; the underlying mechanism is not understood. Here, 
we provide evidence that SL1344 may not subvert plant immunity but, instead, induces weaker responses compared with O157:H7.

\section{MATERIALS AND METHODS}

Plant material and growth conditions. Arabidopsis thaliana (L. Heyhn.) seed were sown in a 1:1:1 ( vol/vol/vol) mixture of growing medium (Redi-earth plug and seedling mix; Sun Gro), fine vermiculite, and perlite. Plants were grown in controlled environmental chambers equipped with humidity control (Percival H2X Two Atomizer Humidifiers; Percival Scientific, Inc., Perry, IA) at $22^{\circ} \mathrm{C}, 60 \pm 5 \%$ relative humidity $(\mathrm{RH})$, and a $12-\mathrm{h}$ photoperiod under light intensity of $100 \mu \mathrm{mol} \cdot \mathrm{m}^{-2} \cdot \mathrm{s}^{-1}$. For all experiments, 4- to 5-week old plants were used. The ecotype Columbia (Col-0; ABRC stock CS60000) was used as a wild-type plant. The Arabidopsis mutant ost1-2 (23) and its wild-type Landsberg erecta (Ler) were a kind gift from Dr. J. Leung at CNRS, France. Hydroponically grown, naturally pest-free lettuce plants (Lactuca sativa 'Butter Lettuce') were obtained from a local grocery store and kept at $4^{\circ} \mathrm{C}$ until prior to experiments.

Bacterial strains and culturing conditions. Wild-type bacterial cells of E. coli O157:H7 strain 86-24 (27) and S. enterica serovar Typhimurium SL1344 (17) were grown in Luria-Bertani medium (tryptone at 10 g.liter ${ }^{-1}$, yeast extract at $5 \mathrm{~g}$ liter ${ }^{-1}$, and $\mathrm{NaCl}$ at 5 g.liter $\left.{ }^{-1} ; \mathrm{pH} 7.0\right)$ at $30^{\circ} \mathrm{C}$ for all experiments. Cells were streaked on solid medium from frozen glycerol stocks for inoculum preparation. Medium was supplemented with spectinomycin $\left(100 \mu \mathrm{g} \cdot \mathrm{ml}^{-1}\right)$ to grow SL1344.
Stomatal assay. To assess the effect of RH on stomatal immunity, plants were acclimated under $100 \mu \mathrm{mol} . \mathrm{m}^{-2} \cdot \mathrm{s}^{-1}$ light, $25^{\circ} \mathrm{C}$ temperature, and varying $\mathrm{RH}(60 \pm 5 \%$ or $>95 \%)$ for $12 \mathrm{~h}$ inside a growth chamber equipped with humidity control (Percival H2X Two Atomizer Humidifiers). RH was monitored with a digital hygrometer (Traceable; VWR International, Inc., West Chester, PA). Stomatal assays were conducted as previously described (5), except that unstained, whole leaves were imaged with a Nikon Eclipse 80i fluorescent microscope (Nikon Corporations, Shinagawa-ku, Tokyo) equipped with long-distance objectives to measure the stomatal aperture width. For stomatal assays performed with dark-closed stomata, plants were inoculated in the morning prior to turning on the lights and kept in the dark for the duration of the experiment.

Bacterial inoculations. Bacterial strains were cultured at $30^{\circ} \mathrm{C}$ in liquid Luria-Bertani medium supplemented with appropriate antibiotics until an optical density at $600 \mathrm{~nm}$ of 0.9 to 1.0 was reached. Bacteria were collected by centrifugation and resuspended in water to the final concentration of $10^{8} \mathrm{CFU} \cdot \mathrm{ml}^{-1}$ containing 0.03\% Silwet L-77 (Lehle Seeds Co., Round Rock, TX) for dip inoculation of plants. Highly humid conditions were obtained by keeping well-watered plants covered with plastic domes in controlled environmental chambers. The level of humidity was monitored with a digital hygrometer (Traceable; VWR). Inoculated plants were immediately incubated under the following conditions: $25^{\circ} \mathrm{C}, 60 \pm 5 \%$ or $>95 \% \mathrm{RH}$, and $12 \mathrm{~h}$ of daily light $\left(100 \mu \mathrm{mol} . \mathrm{m}^{-2} \cdot \mathrm{s}^{-1}\right)$ and kept there for the duration of the experiment. Leaves were surface sterilized in $70 \%$ ethanol for 2 min and
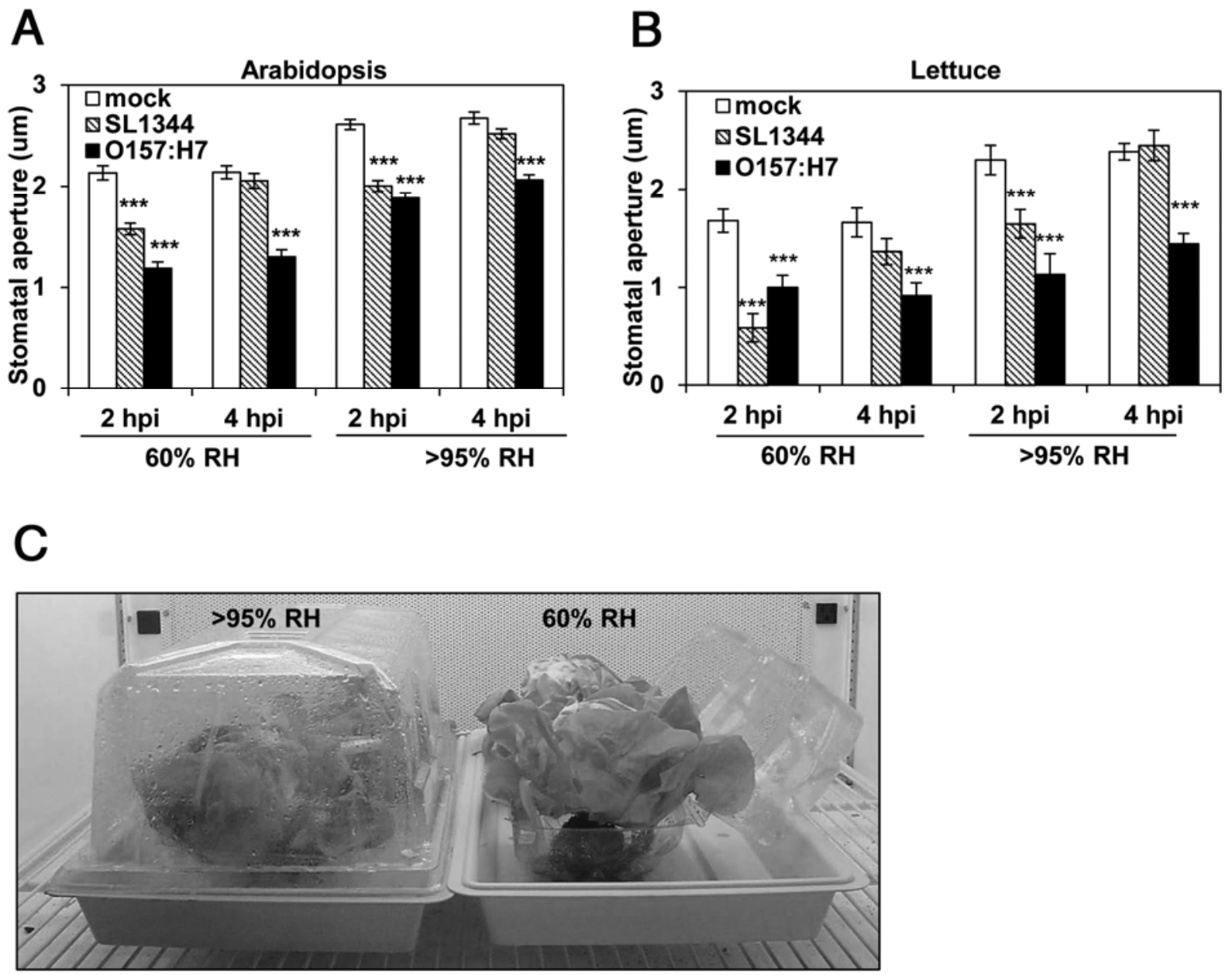

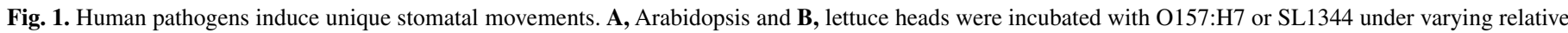

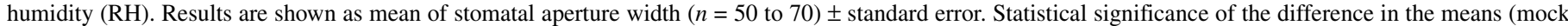

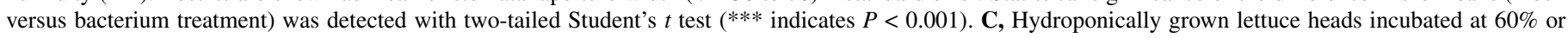
$>95 \%$ RH. Roots of all plants were kept moist for the duration of the experiment. 
bacterial population in the plant apoplast was determined as previously described (16).

Gene expression analysis. Total RNA was extracted from leaves using the RNeasy Plant Mini Kit (Qiagen Inc., Valencia, CA) and quantified using a NanoDrop spectrophotometer (Thermo Scientific, Rockford, IL). Total RNA (1 $\mu \mathrm{g})$ was synthesized into cDNA using the Takara RNA PCR kit (AMV) version 3.0 (Clontech, Mountain View, CA) and diluted to a final concentration of $50 \mathrm{ng} \cdot \mu^{-1}$. Quantitative PCR (qPCR) reaction $(20 \mu \mathrm{l})$ was performed with $10 \mu$ of iTaq Fast SYBR Green Supermix (Bio-Rad, Hercules, CA), $2 \mu \mathrm{l}$ of cDNA template from the reverse transcriptase reaction described above, and $200 \mathrm{nM}$ reverse and forward gene-specific primers. Reactions were carried out in an Applied Biosystems 7300 thermocycler (Applied Biosystems, Foster City, CA) using the following cycling parameter: 1 cycle of
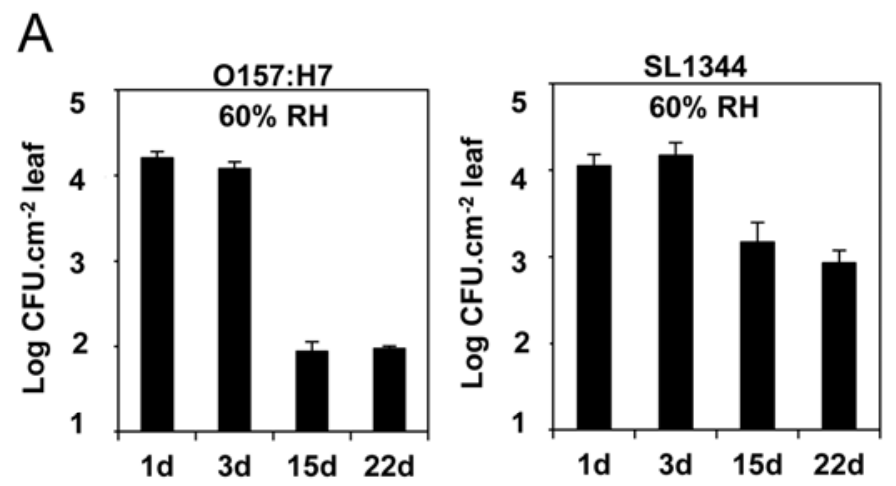

B
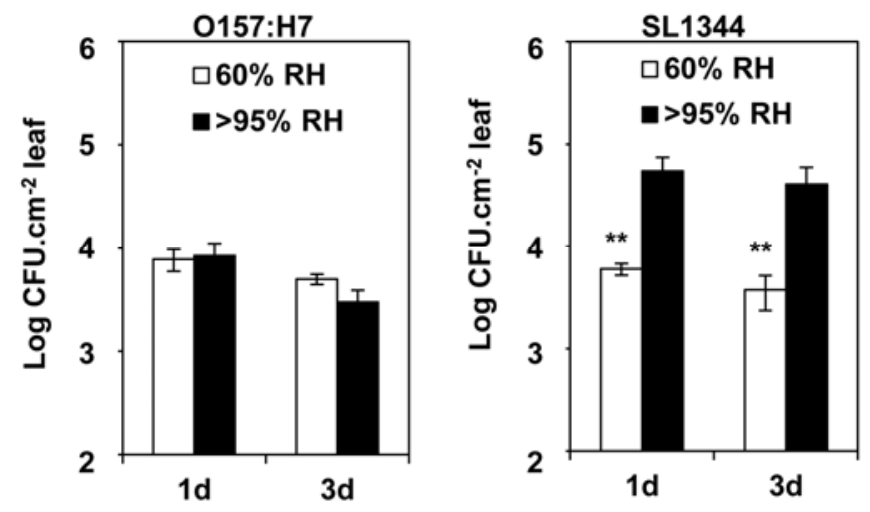

C
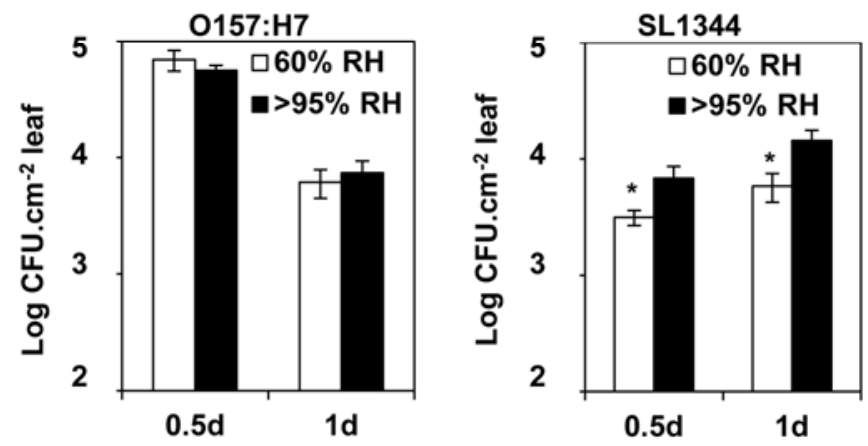

Fig. 2. High relative humidity $(\mathrm{RH})$ favors penetration and survival of SL1344 but not O157:H7. A and B, Arabidopsis and C, lettuce. Bacterial enumeration in the leaf apoplast at different days (d) after dip inoculation with O157:H7 or SL1344 under varying RH. Results are shown as the mean $(n=12) \pm$ standard error. Statistical significance of the difference in the means $(60 \%$ versus $>95 \%$ $\mathrm{RH}$ at each time point) was detected with two-tailed Student's $t$ test (* and ** indicate $P<0.05$ and 0.01 , respectively). $95^{\circ} \mathrm{C}$ for $5 \mathrm{~min}$ and 40 cycles of $95^{\circ} \mathrm{C}$ for $10 \mathrm{~s}$ and $60^{\circ} \mathrm{C}$ for $30 \mathrm{~s}$. Pathogenesis-related 1 (PRI) (At2g14610) gene expression levels relative to the control samples were calculated using the $\Delta \Delta \mathrm{Ct}$ method (18) considering the expression of the housekeeping gene ACT8 (At1g49240) as an internal control. ACT8 primers used were 5'-TTCCGGTTACAGCGTTTGGAGAGA-3' (forward) and 5'-AACGCGGATTAGTGCCTCAGGTAA-3' (reverse) and PRI primers were $5^{\prime}$-CTTGTTCTTCCCTCGAAAGCTCAAGATAGC$3^{\prime}$ (forward) and 5'-GAGCATAGGCTGCAACCCTCTC-3' (reverse). Two biological replicates and three technical replicates were performed.

Statistical analysis. Statistical significance of data from the stomatal assay, bacterial counts in the apoplast, and gene expression was calculated using two-tailed Student's $t$ test. All experiments reported here were repeated at least two times (biological replicates) using a minimum of three technical replicates.

\section{RESULTS}

Human pathogens induce unique stomatal movements. Because leafy vegetables, especially lettuce, are normally maintained at high $\mathrm{RH}$ prior to consumption, we checked for the possibility of Arabidopsis and lettuce to mount stomatal immunity against O157:H7 and SL1344 under varying air RH (Fig. 1). The average stomatal aperture width in mock-inoculated plants was wider under $>95 \% \mathrm{RH}$ than $60 \% \mathrm{RH}$. Nonetheless, live O157:H7 bacterium induced strong stomatal closure in both Arabidopsis (Fig. 1A) and lettuce (Fig. 1B) plants under both RH levels, and most stomata remained closed for the duration of the experiment (4 h). Interestingly, the SL1344 bacterium induced only a transient stomatal closure at $2 \mathrm{~h}$ and stomatal aperture width returned to measurements similar to that of the water control in both plants under both $\mathrm{RH}$ at $4 \mathrm{~h}$ post-inoculation (Fig. 1).

We next determined bacterial titers in the apoplast of dipinoculated leaves, which allows bacterial penetration through the stomata, closely mimicking natural infection conditions. O157:H7 and SL1344 did not proliferate inside Arabidopsis and the bacterial population declined as the plant started to senesce. The O157:H7 population, however, drastically declined (100-fold) $\approx 15$ days after inoculation, whereas the SL1344 population reduced 10-fold in the same time period (Fig. 2A). Because these bacteria did not multiply aggressively in the apoplast and we observed a very similar kinetics of stomatal movement under both RH (Fig. 1), we expected that apoplastic bacterial enumeration would be also very similar independent of the RH. Although this was true for O157:H7, high RH favored a significantly larger $(P<$ $0.05)$ apoplastic bacterial population of SL1344 in Arabidopsis (Fig. 2B). Unlike Arabidopsis plants, lettuce heads cannot be maintained at $60 \% \mathrm{RH}$ for a period longer than $24 \mathrm{~h}$ because they start to wilt; therefore, we stopped the experiment at that time point. Nonetheless, the same trend in bacterial population counts in response to RH levels was observed in both plants (Fig. 2B and C).

SL1344 cannot actively open stomata. The results above suggest that SL1344 could be able to overcome stomatal immunity and actively open the pore, similar to phytopathogenic bacteria such as Pseudomonas syringae $(20,22)$ and Xanthomonas campestris (11). We tested the hypothesis that SL1344 can actively open stomata by performing a stomatal assay under darkness at $60 \% \mathrm{RH}$. This bacterium was unable to open darkclosed stomata (Fig. 3); therefore, we reasoned that this SL1344 triggers a weak immunity in the plant and the light stimulus is quickly prioritized by the guard cell, resulting in re-opening of the stomata (Fig. 3), and O157:H7 induces a strong stomatal immune response that cannot be overcome by light (Fig. 1).

To support the idea that guard cells can prioritize their response when challenged with biotic and abiotic stresses, we performed stomatal assays with flg22, a conserved 22-amino acid peptide of 
the flagellin subunit and a general inducer of a plant's innate immune responses (31). Arabidopsis and lettuce stomata significantly closed in response to flg22 compared with the water control (Fig. 4). However, we observed that high RH (>95\%) diminished the effect of flg22 at a low concentration $(2 \mu \mathrm{M})$. Increasing the concentration of flg 22 to $10 \mu \mathrm{M}$ caused the stomata to close to the same extent, independent of the RH level used (Fig. 4). These results suggest that strong PTI overrides the effect of high RH in opening stomata, and guard cells prioritize their response to different external stimuli showing various degrees of stomatal immunity. Therefore, it is likely that the re-opening of stomata during incubation with SL1344 (Fig. 1) represents a weak stomatal immune response to SL1344.

Stomatal immunity reduces penetration of human pathogens into leaves. Because $\mathrm{O} 157: \mathrm{H} 7$ induces strong stomatal closure in Arabidopsis and lettuce plants even under high RH, we could not determine whether this layer of defense is effective in diminishing contamination of plant internal tissues by human bacterial pathogens using only wild-type plants. To test this hypothesis, we conducted stomatal and pathogenesis assays (Fig. 5) with the Arabidopsis mutant ost 1-2 (23) that is unable to close stomata in response to PAMPs (22). These experiments were performed under moderate RH $(60 \%)$, which does not favor bacterial penetration in the wild-type plant (Fig. 2). Because ost 1-2 plants naturally have mostly open stomata, we first determined that they can be maintained at $60 \%$ RH without wilting (Fig. 5A). The results showed that stomata in ost 1-2 plants do not close in response to O157:H7 or SL1344 (Fig. 5B) and these plants support higher bacterial titer in their apoplast compared with the wild-type plant Ler (Fig. 5C). Taken together, these findings provide direct genetic evidence in support of our hypothesis.

0157:H7 induces a higher level of $P R 1$ gene expression than SL1344. To assess whether human pathogens can also regulate Arabidopsis defense responses in whole leaves, we evaluated the expression level of the Arabidopsis marker gene PRl (At2g14610) that is associated with immunity against bacteria. Reverse-transcription qPCR analysis indicated that both O157:H7 and SL1344 induce an early expression of the PRI gene; however, O157:H7 induced a higher expression level of PRl than SL1344 (Fig. 6). This result suggests that the plant may activate its defense more effectively against O157:H7 than SL1344. It also may explain, at least in part, the fact that the SL1344 population persists at $\approx 1 \log$ higher than the O157:H7 population in the apoplast of Arabidopsis at 15 to 22 days after inoculation even though the inoculum concentration $\left(10^{8}\right.$ CFU.ml $\left.{ }^{-1}\right)$ was the same for both bacteria (Fig. 2A).

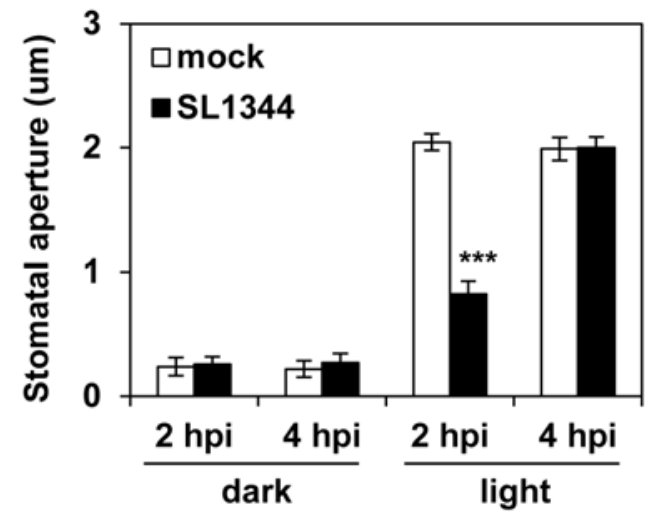

Fig. 3. SL1344 cannot actively open stomata. Arabidopsis plants were dip inoculated with SL1344 and maintained at $60 \%$ relative humidity in the dark or under light for the duration of the experiment; hpi $=\mathrm{h}$ post-inoculation. Results are shown as mean of stomatal aperture width $(n=50$ to 70$) \pm$ standard error. Statistical significance of the difference in the means (mock versus bacterium treatment at specific time points) was detected with two-tailed Student's $t$ test (*** indicates $P<0.001$ ).

\section{DISCUSSION}

An increasing number of reports on gastroenteritis outbreaks associated with consumption of fresh produce have been published in the last several years. Although there is no simple or single solution to this problem, one crucial aspect is to understand how human pathogens can penetrate and survive in plant tissues. In this study, we addressed the plant immune response toward two human bacterial pathogens, O157:H7 and SL1344, both at preinvasion (i.e., stomatal immunity) and post-invasion stages of the infection.

Previously, we have demonstrated that O157:H7 induces strong stomatal closure in Arabidopsis leaves until $8 \mathrm{~h}$ post-incubation using water as vehicle to inoculate plants (22). More recently, however, Kroupitski and collaborators (17) have shown that SL1344 does not induce strong stomatal closure in lettuce compared with $P$. syringae pv. tomato DC3000. Because these authors have submerged lettuce leaves into saline bacterial suspension, we suspected that their finding that SL1344 does not close stomata was because the extremely wet conditions would favor stomata to stay open. Therefore, we checked stomatal response under two
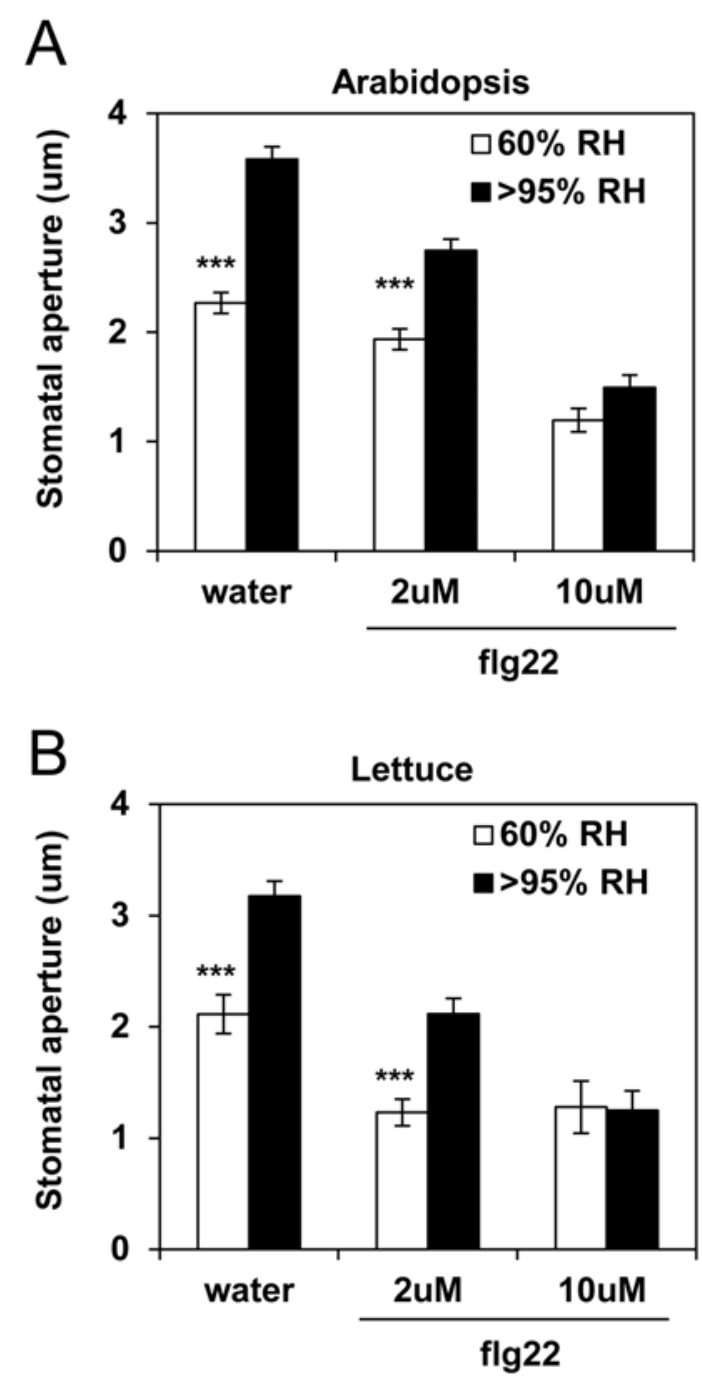

Fig. 4. Strong pathogen-triggered immunity overrides the effect of high relative humidity $(\mathrm{RH})$ in opening stomata. Stomatal response to different concentration of flg22 under varying RHs and constant light. A, Arabidopsis or B, lettuce leaves were floated on either water or flg22 solution and stomatal aperture was measured $4 \mathrm{~h}$ post-incubation. Results are shown as mean of stomatal aperture width ( $n=50$ to 70$) \pm$ standard error. Statistical significance of the difference in the means $(60 \%$ versus $>95 \% \mathrm{RH})$ was detected with twotailed Student's $t$ test $(* * *$ indicates $P<0.001)$. 
levels of RH (Fig. 1C). High RH had a positive effect on stomatal opening, as shown with stomatal aperture width on water-treated plants (Figs. 1A and B and 4). Nonetheless, O157:H7 induced significant stomatal closure and SL1344 induced a transient closure in Arabidopsis and lettuce under both RHs (Fig. 1).

The unique stomatal movement in response to O157:H7 and SL1344 raised the immediate questions "has SL1344 evolved mechanisms to overcome stomatal immunity?" and "do plants efficiently recognize and respond to O157:H7 but not SL1344?" We have shown three pieces of evidence to support the hypothesis that stomatal re-opening in response to SL1344 is due to weak induction of PTI. First, our result shows that SL1344 cannot actively open dark-closed stomata (Fig. 3). Therefore, it is most likely that stomatal re-opening under light is a consequence of a weak stomatal immunity against SL1344, and stomata return to the open state quickly after the immune response phases out. Second, Melotto et al. (22) reported that increasing concentration of lipopolysaccharide (LPS) from Escherichia, Salmonella, and Pseudomonas correlates with increasing stomatal closure under light. Similarly, dose response experiments with flg22 and $P$. syringae pv. tomato DC3000 also positively correlated with stomatal closure (22). In a study to determine the overall transcriptional changes caused by flg22 in Arabidopsis, Denoux et al.

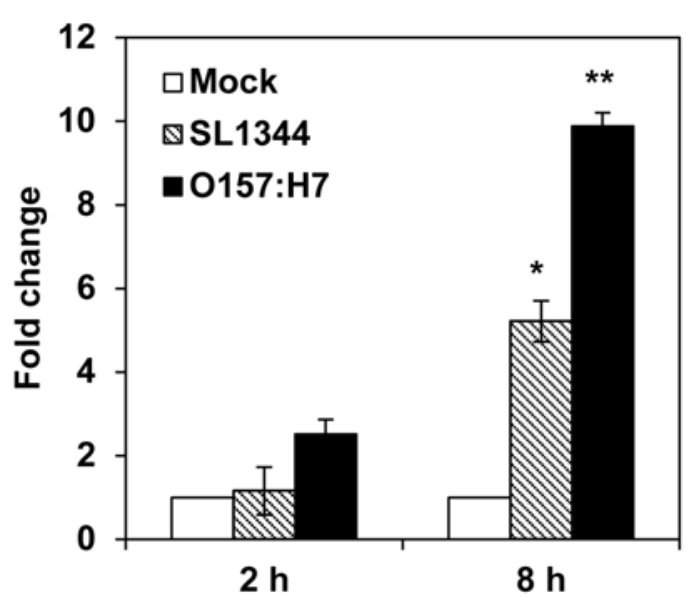

Fig. 6. $\mathrm{O} 157: \mathrm{H} 7$ induces higher level of pathogenesis-related $1(P R 1)$ gene expression than SL1344. Expression of the PRI gene (At2g14610) at 2 and $8 \mathrm{~h}$ post-inoculation with bacteria relative to the mock control as determined by reverse-transcription quantitative polymerase chain reaction. Statistical significance of the difference in the mean expression of $P R 1$ in response to SL1344 and O157:H7 relative to that in the mock control was detected with two-tailed Student's $t$ test $(*$ and $* *$ indicate $P<0.05$ and 0.01 , respectively).
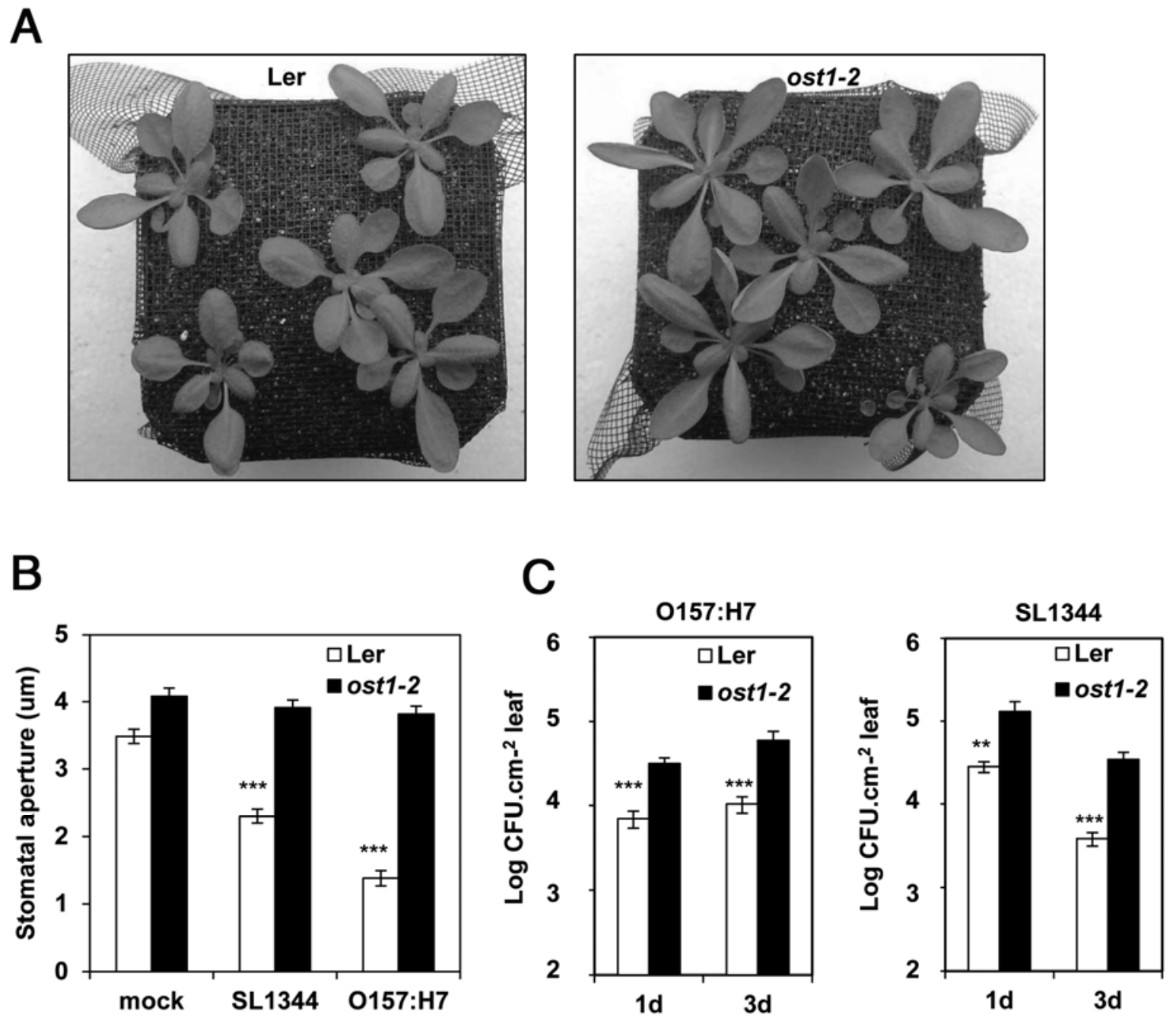

Fig. 5. Stomatal immunity reduces penetration of human pathogens through the leaf epidermis. The ost1-2 and wild-type Landsberg erecta (Ler) plants were dip inoculated with O157:H7 or SL1344. A, Pictures show Ler and ost1-2 mutant plants kept at 60\% relative humidity (RH) for the duration of the experiments. Note that this moderate RH does not cause plants to wilt. B, Stomatal aperture width was measured $2 \mathrm{~h}$ after inoculation with bacteria or water control. Results are shown as mean of stomatal aperture width $(n=50$ to 70$) \pm$ standard error (SE). C, Bacterial enumeration in the leaf apoplast at different days (d) after inoculation. Results are shown as the mean $(n=18) \pm$ SE. Statistical significance of the difference in the means (Ler versus ost $1-2)$ was detected with two-tailed Student's $t$ test (** and $* * *$ indicate $P<0.01$ and 0.001 , respectively). 
(6) concluded that this immune response elicitor changes the magnitude of induction of individual genes in a dose-dependent manner, and the transcriptional responses return to basal level within $24 \mathrm{~h}$ after treatment. In this study, we demonstrate that a low concentration of flg22 $(2 \mu \mathrm{M})$ at $>95 \% \mathrm{RH}$ is not as effective as $10 \mu \mathrm{M}$ flg22 in closing stomata (Fig. 4), suggesting that environmental conditions favoring stomatal opening such as light and high RH can override weak PTI. Consistently, penetration and survival of $\mathrm{O} 157: \mathrm{H} 7$ (that induces a strong response) in the apoplast of Arabidopsis and lettuce was not affected by the $\mathrm{RH}$ (Fig. 2B and C). However, high RH favored SL1344 penetration and survival in both plants (Fig. $2 \mathrm{~B}$ and C), suggesting that $>95 \%$ $\mathrm{RH}$ quickly diminished the effect of a weak PTI caused by SL1344. Third, SL1344 does not induce the expression of the PRl genes, a hallmark of plant immune response, to the same extent as O157:H7 (Fig. 6). Taken together, these findings support the idea that, unlike O157:H7, SL1344 is weakly recognized by Arabidopsis and lettuce, and immune responses in both mesophyll and guard cells are transient. To fully reject the alternative hypothesis that SL1344 evolved mechanisms to suppress plant immunity, it remains to be determined whether SL1344 downregulates genes and metabolic pathways involved in plant defense responses.

We have shown that lettuce is able to mount stomatal immunity against bacteria similar to what has been observed in other plants such as Arabidopsis, tomato, tobacco, soybean, and common bean $(11,19,22,24)$. These results reinforce the notion that stomatal immunity is a widespread mechanism of defense among plants extending to both plant and human pathogens. Interestingly, it seems that the molecular components involved in plant immunity against both types of pathogens are essentially the same. For instance, the guard-cell-specific OST1 kinase is required for stomatal immunity against this broad range of bacteria (22; this study). Likewise, mitogen-activated protein kinases (specifically, MPK3 and MPK6) are required for Arabidopsis stomatal response against $X$. campestris pv. campestris (11) and mesophyll immunity against $S$. enterica serovar Typhimurium 14028 (25). This unique feature of plants could be further explored to improve resistance against pathogen penetration and subsequent contamination and infection of internal tissues.

A recent study has shown that populations of several O157:H7 strains lacking cell surface structures are larger on the wild-type Arabidopsis and induce less $P R$ gene expression than their counterparts with the cell surface structures (26). Similarly, lack of flagellin production or the type three secretion apparatus in $S$. enterica serovar Typhimurium 14028 enhances alfalfa root endophytic colonization (13). Furthermore, the type of $\mathrm{O}$ antigen, specifically O: $1,3,19$, in the LPS moiety of $S$. enterica serovars was shown to be associated with leaf wilting in Arabidopsis, whereas strains that lack the $\mathrm{O}$ antigen (rough strains) or belonging to other serogroups such as SL1344 cause no visible reaction on leaves (2). Therefore, it is possible that some bacterial species may induce stronger immunity than others, depending on how efficiently plants can recognize their MAMPs and trigger defense responses. It is also tempting to speculate that perhaps SL1344 has evolved mechanisms to avoid recognition by plants and is able to penetrate and survive as an endophyte more efficiently than O157:H7.

Finally, as mentioned above, we observed that high $\mathrm{RH}$ favors penetration and survival of SL1344 but not O157:H7 (Fig. 2B and C) and we reasoned that strong induction of PTI by O157:H7 may override the effect of high RH on stomatal opening. However, we cannot rule out other factors that contribute to successful penetration of SL1344 into leaves such as the ability to move on the leaf surface, chemotaxis toward nutrients exiting through the stomatal pore (17), and the overall fitness of these bacteria in the plant environment. Certainly, the ability of the plant to recognize and activate its immune system against human pathogens also contributes to the outcome and severity of plant infections.

\section{ACKNOWLEDGMENTS}

This work was supported by funding from the U.S. National Institute of Allergy and Infectious Disease (5R01AI068718) and University of Texas start-up funds to M. Melotto. We thank V. Sperandio, S. Sela, and J. Leung for providing Escherichia coli 0157:H7, Salmonella enterica serovar Typhimurium SL1344, and ost1-2 seed, respectively; and two anonymous reviewers and $\mathrm{M}$. Brandl for their critiques and constructive comments.

\section{LITERATURE CITED}

1. Barak, J. D., and Schroeder, B. K. 2012. Interrelationships of food safety and plant pathology: the life cycle of human pathogens on plants. Annu. Rev. Phytopathol. 50:241-266.

2. Berger, C. N., Brown, D. J., Shaw, R. K., Minuzzi, F., Feys, B., and Frankel, G. 2011. Salmonella enterica strains belonging to O serogroup 1,3,19 induce chlorosis and wilting of Arabidopsis thaliana leaves. Environ. Microbiol. 13:1299-1308.

3. Brandl, M. T., and Mandrell, R. E. 2002. Fitness of Salmonella enterica serovar Thompson in the cilantro phyllosphere. Appl. Environ. Microbiol. 68:3614-3621.

4. CDC. 2010. Surveillance for foodborne disease outbreaks: United States. 2007. Morb. Mortal. Wkly. Rep. 59:973-1008.

5. Chitrakar, R., and Melotto, M. 2010. Assessing stomatal response to live bacterial cells using whole leaf imaging. J. Vis. Exp. 44 pii:2185. Online publication. doi: $10.3791 / 2185$

6. Denoux, C., Galletti, R., Mammarella, N., Gopalan, S., Werck, D., De Lorenzo, G., Ferrari, S., Ausubel, F. M., and Dewdney, J. 2008. Activation of defense response pathways by OGs and flg22 elicitors in Arabidopsis seedlings. Mol. Plant 1:423-445.

7. Doyle, M. P., and Erickson, M. C. 2008. Summer meeting 2007-the problems with fresh produce: an overview. J. Appl. Microbiol. 105:317330.

8. Duffy, E. A., Cisneros-Zevallos, L., Castillo, A., Pillai, S. D., Ricke, S. C., and Acuff, G. R. 2005. Survival of Salmonella transformed to express green fluorescent protein on Italian parsley as affected by processing and storage. J. Food Prot. 68:687-695.

9. Erickson, M. C. 2012. Internalization of fresh produce by foodborne pathogens. Annu. Rev. Food Sci. Technol. 3:283-310.

10. Grant, M. R., and Jones, J. D. G. 2009. Hormone (dis)harmony moulds plant health and disease. Science 324:750-752.

11. Gudesblat, G. E., Torres, P. S., and Vojnov, A. A. 2009. Xanthomonas campestris overcomes Arabidopsis stomatal innate immunity through a DSF cell-to-cell signal-regulated virulence factor. Plant Physiol. 149: 1017-1027.

12. Hettenhausen, C., Baldwin, I., and Wu, J. 2012. Silencing MPK4 in Nicotiana attenuata enhances photosynthesis and seed production but compromises abscisic acid-induced stomatal closure and guard cell-mediated resistance to Pseudomonas syringae pv. tomato DC3000. Plant Physiol. 158:759-776.

13. Iniguez, A. L., Dong, Y., Carter, H. D., Ahmer, B. M. M., Stone, J. M., and Triplett, E. W. 2005. Regulation of enteric endophytic bacterial colonization by plant defenses. Mol. Plant-Microbe Interact. 18:169-178.

14. Itoh, Y., Sugita-Konishi, Y., Kasuga, F., Iwaki, M., Hara-Kudo, Y., Saito, N., Noguchi, Y., Konuma, H., and Kumagai, S. 1998. Enterohemorrhagic Escherichia coli $\mathrm{O} 157: \mathrm{H} 7$ present in radish sprouts. Appl. Environ. Microbiol. 64:1532-1535.

15. Jones, J. D. G., and Dangl, J. L. 2006. The plant immune system. Nature 444:323-329.

16. Katagiri, F., Thilmony, R., and He, S. Y. 2002. The Arabidopsis Book. American Society of Plant Biologists, Rockville, MD, USA. Online publication. doi:10.1199-tab.0039 (http://www.aspb.org/publications/ arabidopsis/)

17. Kroupitski, Y., Golberg, D., Belausov, E., Pinto, R., Swartzberg, D., Granot, D., and Sela, S. 2009. Internalization of Salmonella enterica in leaves is induced by light and involves chemotaxis and penetration through open stomata. Appl. Environ. Microbiol. 75:6076-6086.

18. Livak, K. J., and Schmittgen, T. D. 2001. Analysis of relative gene expression data using real-time quantitative PCR and the 2(-Delta Delta C(T)) method. Methods 25:402-408.

19. McDonald, K. L., and Cahill, D. M. 1999. Evidence for a transmissible factor that causes rapid stomatal closure in soybean at sites adjacent to and remote from hypersensitive cell death induced by Phytophthora sojae. Physiol. Mol. Plant Pathol. 55:197-203.

20. Melotto, M., and Kunkel, B. N. 2013. Virulence strategies of plant pathogenic bacteria. The Prokaryotes, 4th ed. Springer-Verlag, Berlin. Online publication. doi:10-1007/978-3-642-30141-4_62

21. Melotto, M., Underwood, W., and He, S. Y. 2008. Role of stomata in plant 
innate immunity and foliar bacterial diseases. Annu. Rev. Phytopathol. 46:101-122.

22. Melotto, M., Underwood, W., Koczan, J., Nomura, K., and He, S. Y. 2006. Plant stomata function in innate immunity against bacterial invasion. Cell 126:969-980

23. Mustilli, A. C., Merlot, S., Vavasseur, A., Fenzi, F., and Giraudat, J. 2002. Arabidopsis OST1 protein kinase mediates the regulation of stomatal aperture by abscisic acid and acts upstream of reactive oxygen species production. Plant Cell 12:3089-3099.

24. Schellenberg, B., Ramel, C., and Dudler, R. 2010. Pseudomonas syringae virulence factor syringolin A counteracts stomatal immunity by proteasome inhibition. Mol. Plant-Microbe Interact. 23:1287-1293.

25. Schikora, A., Carreri, A., Charpentier, E., and Heribert, H. 2008. The dark side of the salad: Salmonella typhimurium overcomes the innate immune response of Arabidopsis thaliana and shows an endopathogenic lifestyle. PLoS ONE 3:e2279.

26. Seo, S., and Matthews, K. R. 2012. Influence of the plant defense response to Escherichia coli $\mathrm{O} 157: \mathrm{H} 7$ cell surface structures on survival of that enteric pathogen on plant surfaces. Appl. Environ. Microbiol. 78:5882-5889.

27. Sperandio, V., Torres, A. G., Girón, J. A., and Kaper, J. B. 2001. Quorum sensing is a global regulatory mechanism in entrohemorrhagic Escherichia coli O157:H7. J. Bacteriol. 183:5187-5197.

28. Warriner, K., and Namvar, A. 2010. The tricks learnt by human enteric pathogens from phytopathogens to persist within the plant environment. Curr. Opin. Biotechnol. 21:131-136.

29. Zeng, W., Melotto, M., and He, S. Y. 2010. Plant stomata: A checkpoint of host immunity and pathogen virulence. Curr. Opin. Biotechnol. 21:599603

30. Zhang, H., Dong, S., Wang, M., Wang, W., Song, W., Dou, X., Zheng X., and Zhang, Z. 2010. The role of VACUOLAR PROCESSING ENZYME $(V P E)$ from Nicotiana benthamiana in the elicitor-triggered hypersensitive response and stomatal closure. J. Exp. Bot. 61:3799-3812

31. Zipfel, C., Robatzek, S., Navarro, L., Oakeley, E. J., Jones, J. D., Felix, G., and Boller, T. 2004. Bacterial disease resistance in Arabidopsis through flagellin perception. Nature 428:764-767. 